\title{
Representaciones sociales sobre la formación inicial docente: evaluación diagnóstica a estudiantes que ingresan a carreras pedagógicas en dos universidades chilenas ${ }^{1}$
}

\section{Social Representations about Initial Teacher Training : Diagnostic Assessment of Students who Enroll in Pedagogical Programs at two Chilean Universities}

\author{
Pedro Sandoval-Rubilar y \\ Ana Carolina Maldonado \\ Universidad del Bío-Bío, Chile
}

\author{
Alex Pavié-Nova, \\ Claudia Rubio-Benítez y \\ Claudia Gonzáles-Castro \\ Universidad de Los Lagos, Chile
}

\begin{abstract}
Resumen
Este estudio es de tipo descriptivo e interpretativo y da cuenta de los resultados de las representaciones sociales sobre la profesión docente que autorreportan alumnos que ingresan a la formación inicial de profesores en dos instituciones chilenas de educación superior estatales; una de la región de Ñuble y la otra de la Región de Los Lagos. Este estudio surge a partir de la actualización del sistema nacional de aseguramiento de la calidad de la educación, en donde se establece la obligatoriedad de aplicar test de evaluación diagnóstica. Para tal efecto la población estuvo conformada por 834 estudiantes de la cohorte 2018, pertenecientes a 15 carreras de Pedagogía en dos universidades del país. Se aplicó un instrumento escala tipo Likert, validado en una población similar en el año 2017. Para realizar el análisis de la información, se aplicaron métodos descriptivos numéricos e inferenciales. En sus principales conclusiones, se devela representaciones sociales comunes en dimensiones sobre vocación, ejercicio de la profesión, prestigio e imagen social del profesorado, independiente del sexo, de lo que se desprende que los sujetos evaluados conforman una identidad profesional claramente modelada antes de comenzar su formación inicial docente.
\end{abstract}

Palabras clave: Evaluación Nacional Diagnóstica, representaciones sociales sobre la profesión docente, formación inicial docente

\footnotetext{
${ }^{1}$ Este artículo se enmarca en el proyecto de investigación titulado "Representaciones sobre la Profesión Docente que poseen estudiantes que ingresan a la Formación Inicial Docente en universidades del Estado", FONIDE (Fondo de Investigación y Desarrollo en Educación) código FON 181800090, convocatoria $\mathrm{n},{ }^{\circ} 12,2018$

Pedro Sandoval-Rubilar y Ana Carolina Maldonado, Universidad del Bío-Bío, Chile; Alex Pavié-Nova y Claudia Rubio-Benítez, Universidad de Los Lagos, Chile.

La correspondencia en relación con este artículo se dirige a Pedro Sandoval-Rubilar, Universidad del Bío-Bío, dirección electrónica: psandoval@ubiobio.cl
} 


\begin{abstract}
:
This descriptive and interpretative study accounts for results of social representations regarding the teaching profession which students of initial teacher training report in two Chilean public institutions of Higher Education, from Ñuble and Los Lagos regions. This study arises from the updating of the National Educational Quality Assurance System, which establishes the obligation to apply a diagnostic test. To this end, the population was composed of 834 students from the 2018 cohort of 15 pedagogical programs from two national universities. A Likert-like scale instrument was applied, it was validated in a similar population in 2017. Numerical descriptive and inferential methods were applied to analyze the information. Generally concluding, common social representations are revealed about vocation, professional performance, prestige and social image of teachers regardless of sex; it suggests that the evaluated subjects shape a clearly modelled professional identity before starting their Initial Teacher Training.
\end{abstract}

Keywords: National Assessment Diagnostic, Representations about the Teaching Profession, Initial Teacher Training

En la década de 1990, en América Latina, organizaciones internacionales como el Banco Mundial, Organización de las Naciones Unidas para la Educacion, la Ciencia y la Cultura (UNESCO), Organización para la Cooperación y el desarrollo económico (OCDE), entre otras, introducen el concepto de calidad como eje orientador de las políticas educativas del continente (Reimers, 2000). La calidad más la eficiencia y la equidad constituyeron el marco referencial de todas las reformas educacionales. El estudio de los factores que la favorecen orientó el debate, principalmente, hacia la revisión de los procesos educativos y las competencias profesionales de los educadores (Álvarez \& Ruiz-Casares, 1997).

La relación establecida entre calidad de la educación y la calidad de la docencia ha sido fundamentada por diversos autores como Ryans (1967), Contreras (1985), Casassus (2003), Barber y Mourshedd (2008) entre otros. Así, se gestaron en América Latina numerosas políticas de estabilidad laboral, capacitación y perfeccionamiento de los profesores en servicio (Sandoval, 2009). Chile también formó parte activa en las propuestas para mejorar la calidad de la educación centradas en la calidad del desempeño docente. Algunas acciones realizadas vinculadas al profesorado fueron la creación de la Ley de Estatuto Docente, la asignación de premios de excelencia y estímulos al perfeccionamiento dentro y fuera del país (Sandoval, 2009).

A pesar de los innegables avances en el área, la calidad y la equidad en educación, en gran parte del continente, "siguen siendo propósitos y todavía no constituyen plenamente una solución, dado que los esfuerzos realizados no han servido del todo, para garantizar un desarrollo educativo sostenido" (Vaillant, 2005 , p. 2). Evidencia de lo anterior, es el reposicionamiento de la discusión sobre calidad que se impone con fuerza en la agenda gubernamental chilena, posterior a los movimientos estudiantiles de los años 2006 y 2011. Las tensiones originadas por las movilizaciones obligaron discutir las concepciones en torno a la educación desde lo económico, lo político y lo educativo. Se cuestionó la idea de calidad que se venía construyendo hasta el momento (Rifo, 2013). Una de las respuestas ministeriales a la demanda estudiantil, en el año 2006, fue la creación de un Consejo Asesor Presidencial para la Calidad de la Educación dedicado a la revisión, replanteamiento y discusión acerca de las decisiones político-gubernamentales en dicha materia (Valdebenito, 2011). En este contexto, se abordaron diversos aspectos; por ejemplo, la creación 
de organismos fiscalizadores; la evaluación del sistema de gestión de las escuelas y, en especial, el seguimiento a la docencia. Se situó al profesorado, una vez más, en el centro de la discusión.

En la última década, la preocupación del Estado de Chile en asuntos referentes a la docencia se concreta en dos líneas de acciones: (a) monitoreo de la idoneidad de los docentes en ejercicio; y (b) pertinencia de las trayectorias de formación docente. Al interior de la primera línea de acciones, a la evaluación docente implementada en el año 2005, se sumó la promulgación de la Nueva Carrera Docente en el año 2016, que enfatiza en la profesionalización de los profesores en ejercicio. La ley surge de la sentida necesidad de valorar la docencia y el carácter estratégico de dicha profesión mediante políticas que favorezcan las condiciones laborales y de desarrollo profesional acordes a la envergadura de la tarea (Rufinelli, 2016).

Dentro de la línea de acciones orientadas a mejorar los procesos formativos de los futuros docentes, una de las acciones en proceso de implementación es la Evaluación Nacional Diagnóstica (END) prescrita en la actualización de la ley sobre Sistema Nacional de Aseguramiento de la Calidad de la Educación (Ministerio de Educación de Chile, 2016). En ella, se espera que las instituciones formadoras de profesores apliquen evaluaciones al inicio y al término de la trayectoria de formación con la finalidad de recoger insumos para mejorar el currículum y los procesos formativos.

Si bien los esfuerzos realizados por mejorar la FID corresponden con la iniciativa de mejorar la calidad profesional de los egresados, es necesario considerar que, en el caso de las pedagogías, la formación inicial no logra erradicar las representaciones sociales y creencias que los profesores en formación traen de sus doce años de escolaridad previa. Si las prácticas y las conductas se cimientan en las representaciones y las creencias que les otorgan sentido (Banchs, 1986), el paso por la universidad parece ser un periodo extremadamente breve para reconceptualizar y reconstruir dichas representaciones sociales ancladas a experiencias escolares anteriores. Estudios demuestran que existe una tendencia en los profesores a desarrollar prácticas de enseñanza muy parecidas a aquellas con las que ellos aprendieron, y que están en directa relación con la concepción de ser docente que han construido a lo largo de su vida (Brunner, 1996; Pozo, 2008, 2009, 2014; Rusell, 2014). La experiencia de la escuela tiene un fuerte impacto en las representaciones con que ingresan los estudiantes a la carrera de pedagogía (Sandoval et al., 2020) y han demostrado ser altamente persistentes a pesar de los esfuerzos de los procesos formativos universitarios. En consideración a lo anterior, se afirma que el proceso de convertirse en profesor se inicia antes del ingreso a la FID, en una etapa previa a la universidad, en donde se vivencian una serie de experiencias que construyen la idea acerca de lo que significa ser profesor (Bristzman, 2003; Caine $\&$ Steves, 2009).

Sin embargo, las personas también son agentes activos de sus representaciones. Al comprometer su pensamiento en procesos epistemológicos que les permiten dejar de reproducir su entorno social simbólico de manera habitual y automática, actúan sobre su realidad y reconstruyen dichas representaciones sociales (Marková, 1996). Por ello, en el contexto chileno, y ante el declarado interés en fortalecer la FID, resulta de interés indagar en las representaciones sociales con que estudiantes ingresan a las carreras de pedagogía, más allá de las pruebas estandarizadas en las que las políticas nacionales han enfatizado. 
Acercarse a las representaciones sociales de los estudiantes permite anticipar determinadas prácticas docentes, como también ajustar los procesos formativos al otorgar espacios explícitos para reflexionar, reconstruir y resignificar aquellas representaciones sociales implícitas de los estudiantes. Este trabajo se propone avanzar en esa dirección. Indaga en las representaciones sociales acerca de la docencia, las opiniones y las valoraciones respecto a su profesión al momento de ingresar a estudiar pedagogía. Especial atención se le entrega al concepto de vocación, como elemento determinante en la elección de una carrera pedagógica y la permanencia en el ejercicio docente (Ávalos \& Sotomomayor, 2012).

\section{Objetivo general}

Comparar las representaciones sociales sobre la profesión docente, que han elaborado los estudiantes que ingresan a estudiar carreras de Pedagogías, en dos universidades del Estado de la zona centro sur del país.

\section{Objetivos específicos}

Identificar las representaciones sociales sobre la profesión docente que han elaborado estudiantes que ingresan a estudiar carreras de Pedagogías a la Universidad de Los Lagos en la ciudad de Osorno, Chile y la Universidad del Bío-Bío, en la ciudad de Chillán, Chile.

Describir las representaciones sociales sobre la profesión docente que han elaborado estudiantes que ingresan a estudiar carreras de Pedagogías a la Universidad de Los Lagos en la ciudad de Osorno, Chile y la Universidad del Bío-Bío en la ciudad de Chillán, Chile.

Comparar las representaciones sociales acerca de la profesión docente que han elaborado estudiantes que ingresan a estudiar carreras de pedagogías a la Universidad de Los Lagos en la ciudad de Osorno, Chile y la Universidad del Bío-Bío, en la ciudad de Chillán, Chile.

\section{Marco referencial sobre representaciones sociales de la profesión docente}

En el campo de la sociología la discusión referente a la relación entre lo colectivo y lo individual, como diálogo y disputa de los campos simbólicos a los que refiere el pensamiento, se inicia con los postulados de Durkheim (1897/1987, 1895/2001), que incorporan la interacción social como determinante de las experiencias del sujeto y su comprensión del mundo. El contexto social, para el autor, está expuesto a procesos de interpretación colectivos, que construyen representaciones que determinan a los sujetos y a su forma de concebir esos contextos.

Los postulados de Durkheim, Berger y Luckmann definieron la sociedad como un producto humano, que en la intersubjetividad se convierte en una realidad objetiva, con estructuras y límites definidos. Estas estructuras determinan la subjetividad y la forma en que los sujetos se desenvuelven en ella: "la sociedad es una realidad objetiva, el hombre es un producto social" (Berger \& Luckmann, 1993, p. 61). Si bien el concepto de Representaciones Sociales (RS) fue acuñado por Moscovici, en 1962, para referirse al pensamiento social desde una perspectiva constructivista, fue posterior a las lecturas de Berger \& Luckmann, quienes desarrollaron la idea de RS como: 
... un corpus organizado de conocimientos y una de las actividades psíquicas gracias a las cuales los hombres hacen inteligible la realidad física y social, se integran en un grupo o en una relación cotidiana de intercambios, liberan los poderes de su imaginación (Moscovici, 1979, p. 18).

El interés investigativo del autor fue la "construcción social de la realidad y cómo las personas construyen y son construidas al interior del sentido común" (Araya, 2002, p. 13). Le asigna al sentido común la categoría de pensamiento social, con estructuras y jerarquías cualitativamente equiparable a cualquier otra forma de conocimiento (Moscovici, 1998). Jodelet complementa los postulados de Moscovici, abordando el sentido común como conocimiento espontáneo, habitualmente concebido en oposición al pensamiento científico, pero con la capacidad de estructurar prácticas y experiencias cotidianas de los sujetos:

... este conocimiento se constituye a partir de nuestras experiencias, pero también de las informaciones, conocimientos y modelos de pensamiento que recibimos y transmitimos a través de la tradición, la educación y la comunicación social. De este modo, ese conocimiento es en muchos aspectos un conocimiento socialmente elaborado y compartido (Jodelet, 1986, p. 473).

Al interior de las (RS) distingue tres dimensiones: (a) actitud, (b) información y (c) campo de representación (Moscovici, 1979). (a) La actitud refiere a la orientación positiva o negativa de una representación. Corresponde a la dimensión afectiva que clasifica la realidad material y social de forma simbólica, favorable o desfavorablemente (Mora, 2002); (b) La información refiere a la cantidad y organización de los conocimientos de una persona o grupo social sobre un objeto o situación determinada. Esta dimensión reconoce la clasificación de determinados conceptos en prejuicios o estereotipos vinculados a la dimensión actitudinal anterior (Araya, 2002); (c) El campo de representación constituye la estructura jerárquica que organiza actitudes e información. Incluye el conjunto de opiniones, imágenes, creencias, vivencias y valores presentes en una misma representación social, organizados en un esquema figurativo construido en el proceso de objetivación. Este esquema le confiere "significado a los demás elementos presentes en el campo de la representación" (Araya, 2002, p. 41).

Explorar las representaciones sociales "tiene un sentido práctico, concurrente a la construcción de una realidad común de un conjunto social" (Jodelet, 1986, p. 36). Implica esto el acceso a una galería mental de representaciones sociales jerarquizadas y estructuradas que corresponde a un determinado grupo de pertenencia (Domínguez, 2001). En el área de la educación, las sociales tienen especial relevancia en tanto favorecen y reproducen un determinado modelo docente, construido sobre experiencias e interacciones de los sujetos en sus trayectorias escolares y vivencias cotidianas, permitiendo anticipar su desempeño profesional (Kaplan, 1997).

En coherencia con lo anterior, este trabajo pretende acceder a las representaciones sociales acerca de la profesión docente, específicamente en torno a tres objetos/contenidos de representación asociadas a ella: vocación docente, ejercicio profesional docente y autoimagen/prestigio social, que se construyen al interior de lo que habitualmente denominamos sentido común en dos de las tres dimensiones señalas. Explora en la dimensión actitud para reconstruir disposiciones y valoraciones conferidas a la profesión en torno a la vocación, el ejercicio profesional docente y autoimagen/prestigio social. Explora también la dimensión información para indagar en el conocimiento social que los sujetos han aprehendido en su 
contexto social, respecto al ejercicio de la profesión docente. De esta manera, se avanza en la reconstrucción de la interpretación del campo de representación de la profesión que han elegido estudiar.

\section{Acerca de la vocación docente}

Definir vocación profesional es una tarea compleja que puede asumir dos perspectivas. La primera de ellas se posiciona desde la endoferencia. Comprende la vocación como una característica intrínseca al sujeto. Se refiere a la relación entre aptitudes naturales y las exigencias de una profesión medible a través de test psicométricos (Lobato, 2002; Rivas, 1998). La segunda perspectiva, se sitúa en la exoferencia. Concibe la vocación como una construcción a lo largo de diversas etapas, de acuerdo con diferentes niveles de acercamiento específico a las profesiones (Recarey, Del Pino \& Rodríguez, 2011). Considera también la inclinación cognoscitiva y afectiva de la personalidad hacia el área de estudio y la valoración social de la profesión con la cual es posible desarrollar sentimientos de pertenencia o rechazo.

Coherente con esta segunda perspectiva, Sánchez (2002, p. 206) define vocación como "una parte importante de las características personales y sociales del sujeto, así como del proceso de socialización del mismo". Por su parte, González $(2017$, p. 29) se refiere a la vocación como "el resultado de un proceso de construcción entre el individuo y su contexto, tanto social como político, económico, geográfico, educativo y psicológico, a través de una relación de mutua influencia”. Según lo anterior, la vocación se desarrolla mediante el transcurso de una interacción sostenida del sujeto y su contexto, a través del cual va estableciendo relaciones cognitivas y afectivas, que se fortalecen en la medida en que se profundiza en el quehacer propio de estas relaciones.

Respecto a la vocación docente, esta es reconocida como uno de los factores fundamentales al ingreso a una carrera pedagógica universitaria (Ávalos, 2014; González \& González, 1993, citados en Sánchez, 2002; Sotomayor, 2013). Existe una sobrevaloración de la vocación pedagógica por sobre la profesionalización. Es habitual la creencia de que las cualidades innatas del profesor son más relevantes que el desarrollo profesional (Caena, 2014; Schaffer, Gleich-Bope \& Copich, 2014).

De acuerdo con Sánchez (2002), la vocación docente se desarrolla en tres etapas (a) prevocacional, (b) perivocacional y (c) vocacional. La etapa prevocacional implica el descubrimiento de la docencia y la observación hacia sus propios maestros y profesores. Incluye el periodo de vida anterior al ingreso a la universidad hasta el momento en que se ingresa a una carrera pedagógica. Según Jarauta (2017):

los estudiantes aspiran a ser aquello que conocen... llevan toda la vida en las aulas, conocen el entorno escolar y ciertos estilos docentes. Pero se trata de un conocimiento parcial, sesgado y basado únicamente en su experiencia y rol como alumnos (p. 118).

La etapa perivocacional considera la trayectoria de formación docente. En esta etapa comienza la comprensión acabada de la tarea profesional a través del acercamiento cognitivo a los fundamentos profesionales. Por último, la etapa vocacional refiere a la etapa de ejercicio de la docencia y puesta en práctica de lo aprendido en su formación.

Como se desprende de la teoría, explorar las representaciones sociales referentes a la vocación profesional en la etapa prevocacional permite develar presupuestos que inciden en la elección de la carrera universitaria. Aporta, además, a evidenciar la construcción de una imagen de la profesión que 
puede ser determinante de un ejercicio docente más o menos adecuado a las demandas sociales. Permite a las instituciones formadoras contar con información oportuna para crear y recrear los conocimientos y valoraciones del estudiantado a través de la reflexión y el cuestionamiento de aspectos relacionados con su vocación). La posterior intervención en la etapa perivocacional, de acuerdo con la información recogida, puede ser decisiva para convertirse en continuadores de los estilos pedagógicos previamente experimentados o aspirar a ser opositores a las experiencias de su escolarización.

\section{Acerca del ejercicio profesional docente}

El ejercicio profesional docente, o profesionalidad docente, transita entre la comprensión de la docencia entendida como un arte y la docencia como habilidad adquirida. Núñez (2004) relaciona el ejercicio profesional con identidad profesional e identifica cuatro formas de entenderla, según las fases históricas por las que ha transitado el profesorado en Chile. En una primera fase, y asociado con el protagonismo de la iglesia en la educación, la profesión docente se asocia a un apostolado vinculado a un conjunto de virtudes morales.

En una segunda etapa, con el surgimiento del estado docente, el profesional de la educación es símil del funcionario público, encuadrado en estructuras estatales. En la etapa de la masificación de la enseñanza, el ejercicio profesional docente adquiere un carácter técnico, basado en competencias fácilmente logrables. La última fase refiere a la existencia de una base de conocimientos distintivos y propios del profesorado, que caracterizarían su profesionalidad (Ávalos, 2001). De esta manera, se configura una discusión:

...respecto de qué sabe y debe saber un profesor, cuáles son los conocimientos de base que debe poseer, cómo los actualiza y utiliza, en qué condiciones, cómo fortalecer el dominio de ese cuerpo de saberes fundamentales y cómo fortalecer las buenas prácticas pedagógicas (Latorre, 2006, p. 60).

Lo anterior implica que la profesionalización dependerá de decisiones políticas, históricas y culturales que signan y condicionan los programas formativos, sus orientaciones, propósitos y contenidos (Muñoz, González \& Rodríguez, 2018).

Si el ejercicio profesional se relaciona con el dominio de saberes que fundamentarán su desempeño laboral, es necesario pesquisar las representaciones sociales acerca de lo que es el ejercicio profesional de los futuros docente (Vélaz de Medrano \& Vaillant, 2009). Si bien la profesionalización implica la apropiación de saberes adquiridos en la trayectoria formativa, esta puede verse influenciada por las representaciones que los estudiantes han erigido en etapas anteriores. La FID debe procurar espacios de reflexión, actualización y reconceptualización de los conocimientos y habilidades pedagógicas para su futuro ejercicio en los nuevos y los actuales contextos sociales y culturales (García, Domínguez \& Del Toro, 2018).

\section{Acerca de la autoimagen y prestigio social}

En general, la autoimagen (también denominada autoconcepto) se relaciona con la autopercepción acerca de los atributos, los rasgos y las características de sí mismo (Sebastián, 2012); para nuestro estudio, la autoimagen proyectada futura que vislumbra en el estudiante como futuro docente. Sebastián (2012), desde una perspectiva psicológica, plantea que la autopercepción de la profesión es una construcción social que surge de los procesos de interacción con otros, en contextos sociales y culturales 
determinados, que tiene directa incidencia en el desarrollo y ejercicio profesional y, por ende, en la formación de los alumnos. Vaillant (2007) afirma que la conceptualización o la definición de sí mismo, como docente, forma parte de su identidad social.

Junto con lo anterior, la autoimagen de la profesión no solo que se refiere a los autoconocimientos sobre su propia profesión, sino también comporta e incluye otros aspectos actitudinales como la valoración de por parte de los individuos. Esta última, a su vez, estaría influenciada por la valoración o el estatus social que posee la profesión docente en la sociedad (Miranda, 2005). Consecuentemente con ello, la autoimagen de la profesión docente se vincularía al estatus o prestigio social.

\section{Método}

Tal como señalan Taylor y Bogdan (1990), lo que define la metodología es tanto la manera de focalizar los problemas como la forma de buscar las respuestas a los mismos. Por ello, en coherencia con los objetivos del estudio, el diseño de la presente investigación es de tipo descriptivo- interpretativo, puesto que pretende caracterizar las representaciones de los sujetos (objetos de la investigación) y alcanzar una interpretación de ellas desde los supuestos teóricos adoptados en la indagación. En otras palabras, se elaboraron arquetipos interpretativos de las representaciones de los actores involucrados para la formulación de hipótesis interpretativas (Eisner, 1998; Goetz \& Lecompte, 1988; Latorre, Del Rincón \& Amal, 1997; Neiman \& Quaranta, 2006). Desde el punto de vista temporal, el estudio fue de tipo transversal, dado que la recolección de información se realizó una sola vez a todos los estudiantes matriculados en primer año en alguna de las carreras de Pedagogía de la Universidad, quienes contestaron en el mismo momento mediante el uso de soportes informáticos. La consulta se realizó durante el mes de abril del 2018 y se siguió el protocolo de consentimiento informado y confidencialidad de información (Meo, 2010) en coherencia con la política institucional al respecto.

\section{Población y muestra}

La población objetivo del estudio se centra en estudiantes de dos universidades estatales del Centro Sur de Chile. Los criterios de inclusión correspondieron a que fueran estudiantes de carreras de pedagogías que ingresan a primer año. Para ello, se incluyó una muestra probabilística en cada universidad. Se consideran los criterios del tamaño de la población objetivo de cada una de ellas. Consta de un muestreo aleatorio simple y la muestra fue calculada con un margen de error del 5\%, una heterogeneidad del 50\% y un nivel de confianza del 95\%. Finalmente, la muestra total determinada corresponde a 414 estudiantes bajo los criterios mencionados. Posterior aplicación del instrumento, la muestra final llegó a un total de 834 estudiantes, quienes ingresaron a las carreras de pedagogías, lo que corresponde a un $93.6 \%$ de la población total objetivo, para la Universidad del Bío-Bío la muestra llegó al 98.3\% de la población y en la Universidad de Los Lagos la muestra fue de un $88.7 \%$ de la población.

En términos de distribución de la muestra final, el 46\% representa la Universidad de Los Lagos y un 54\% de la muestra total a la Universidad del Bío-Bío, universidades del Estado de Chile de regiones del centro sur del país, matriculados en primer año en el periodo académico 2018. La tabla 1 muestra la distribución de estudiantes por universidad con respecto a la población total de matrícula nueva 
informada al 30 de abril del 2018 al Servicio de Información Superior (SIES) y las muestras determinadas y muestras finales obtenidas.

\section{Tabla 1}

Población y muestra obtenida

\begin{tabular}{lcccc}
\multicolumn{1}{c}{ Universidad } & Población & Muestra determinada & Muestra final & $\begin{array}{c}\text { Porcentaje de } \\
\text { representatividad }\end{array}$ \\
\hline Universidad del Bío-Bío & 458 & 210 & 450 & $98.3 \%$ \\
Universidad de Los Lagos & 433 & 204 & 384 & $88.7 \%$ \\
Total Zona Centro Sur & 891 & 414 & 834 & $93.6 \%$ \\
\hline
\end{tabular}

Nota: Elaboración propia.

\section{Instrumento}

En coherencia con los objetivos del estudio, los investigadores han diseñado un instrumento de escala tipo Likert denominada "Escalas de Representaciones sociales sobre la Profesión Docente" . Constó de seis dimensiones, de las cuales se abordaron con mayor especificidad tres de acuerdo con lo planteado previamente en los objetivos abordados en esta investigación, es decir, vocación docente, ejercicio profesional docente y autoimagen/prestigio social de la profesión docente, porque desde la perspectiva de la evaluación diagnóstica de entrada de los estudiantes de Pedagogías, son temas que aun no han sido abordados suficientemente; tal como se indica en la tabla 2. Se deja para un posterior estudio y análisis el abordaje de las otras tres dimensiones restantes del instrumento y del estudio en sí.

\section{Tabla 2}

\section{Especificaciones Escala de representaciones sociales sobre la profesión docente}

\begin{tabular}{lc}
\hline Dimensión & Escalas \\
\hline Vocacional & 9 \\
Desarrollo profesional y económico & 9 \\
Políticas educativas & 9 \\
Ejercicio profesional & 10 \\
Autoimagen y prestigio social & 9 \\
Formación de profesores & 9 \\
Total ítems & 55 \\
\hline
\end{tabular}

Nota: Elaboración propia.

\footnotetext{
${ }^{1}$ La autoría del instrumento es de los académicos autores de este artículo.
} 
La escala presenta un conjunto de proposiciones o afirmaciones para cada dimensión con categorías escalonadas que van desde desfavorable a lo favorable (Totalmente en desacuerdo, En desacuerdo, De acuerdo, Totalmente de acuerdo, No sabe/Sin información del tema). Al contestar, los sujetos evaluados debían graduar su respuesta y se ubican en algún punto de la escala según sus propias representaciones sociales a nivel de información y valoración ${ }^{2}$. Por tanto, cada afirmación proporciona datos sobre la dimensión evaluada. En este caso, la frecuencia de las respuestas de las escalas que contemplan cada dimensión permite identificar la tendencia sobre ella. El tiempo de respuesta del instrumento es de 45 minutos.

Para efectos del estudio, el instrumento fue sometido a validación de contenido y validación estadística durante el año 2017. En la validación de contenido, participaron académicos de las Universidades de Playa Ancha y del Bío-Bío como jueces expertos. Para la validación estadística, se calculó el coeficiente alfa de Cronbach (.82) y el Kaiser-Meyer-Olkin (.87) en una muestra de 1.789 estudiantes, la que correspondió al $41.27 \%$ de los matriculados en carreras de primer año de pedagogía de universidades del estado del país ${ }^{3}$ (Sandoval et al., 2019). En el presente estudio, se vuelve a calcular el alfa Cronbach (.87) y Kaiser-MeyerOlkin (.89) con base en los 450 sujetos de la Universidad del Bío-Bío. Se obtuvieron resultados similares a 2017, lo que permite inferir que el instrumento posee una robustez y consistencia interna en el tiempo; por tanto, es posible sostener que la información obtenida resulta confiable para los efectos del presente estudio.

En cuanto a las variables del estudio, en el presente trabajo, se refieren a las representaciones sociales (RS) sobre la profesión docente a partir de objetos/contenidos representados en torno a la profesión docente: vocacional, ejercicio profesional y auto imagen y prestigio social se constatan 9,10 y 9 ítems respectivamente, ítems que se pueden visualizar en la tabla 2. Cada uno de los objetos/contenidos mencionados son desarrollados en el marco teórico y, para el presente estudio, los ítemes exploran la información y la actitud en torno al conocimiento de sentido común (RS) de los sujetos en relación con la profesión docente. El instrumento fue sometido, además, a validación de juicio de expertos, la cual estuvo compuesta por nueve jueces. De tal forma que, una vez aplicado el instrumento, se procedió a la determinación de la cantidad de adecuaciones en cada uno de los ítemes observados por los expertos definiendo, además, las fortalezas y las limitaciones a priori que se observan por parte de quienes entran a estudiar una carrera pedagógica.

\section{Procedimientos de análisis de la información}

Dado que el instrumento de recolección de información responde a una escala tipo Likert, a fin de develar las representaciones sobre la profesión docente que han construido los estudiantes que ingresan a estudiar alguna de las carreras de Pedagogía, presupone que no existen respuestas correctas o incorrectas en relación con el objeto de estudio. En coherencia, se utilizaron métodos descriptivos enfocados en la frecuencia de la distribución de las respuestas para cada una de las tres dimensiones evaluadas (vocación, ejercicio profesional y autoimagen-prestigio social) con el propósito de facilitar la caracterización

\footnotetext{
${ }^{2}$ Para el presente artículo, se presentarán los resultados de tres objetos/contenidos del instrumento: Vocación docente, Ejercicio profesional docente y autoimagen-Prestigio social de la profesión docente.

${ }^{3}$ El cálculo se basa en la información sistematizada en el Servicio de Información de Educación Superior (SIES) para la matricula primer año 2016 en carreras de Pedagogía y Licenciaturas en Educación (http://www.mifuturo.cl/index.php/informes-sies/ matriculados).
} 
e identificación de algunas representaciones sociales dominantes como si la vocación es influida por padres o parientes cercanos o si la vocación es un requisito fundamental para ejercer la profesión docente o si el ser docente es valorado por el gobierno en general, entre otras.

Específicamente, para tales efectos, las repuestas marcadas por los sujetos se agruparon en tres categorías globalizadoras: "De Acuerdo" y "Totalmente de acuerdo" conformaron una sola categoría denominada Acuerdo; "En desacuerdo" y "Totalmente en desacuerdo" se agruparon en una sola categoría denominada Desacuerdo; y, por último, se asignó la categoría Sin información (S/I), cuando los estudiantes marcaron dicha opción en relación con la afirmación de la escala.

Para el análisis de datos se utilizó el software SPSS versión 21, los métodos utilizados corresponden a estadística descriptiva e inferencial. De acuerdo con la clasificación de las variables, las cuales corresponden a variables categóricas ordinales y una variable de clasificación nominal para diferenciar la Institución de Educación Superior, no es posible dentro de la estadística descriptiva utilizar los estadísticos como media, desviación estándar, entre otros, por lo que se enfoca en las frecuencias de distribución de las respuestas obtenidas. Además, en términos de la estadística inferencial, el uso de la prueba no paramétrica de $U$ de Mann Whitney es debido a la particularidad de las variables, porque corresponden a variables categóricas ordinales con tres categorías y una variable nominal con dos categorías. Por tal motivo, no es posible trabajar con pruebas paramétricas y probar supuestos de normalidad. Esto permitió poder obtener los valores de probabilidad $(p)$ para determinar si existen diferencias estadísticamente significativas en la distribución de las respuestas obtenidas por los estudiantes de cada universidad.

\section{Resultados}

\section{Presentación de datos por dimensiones}

De la muestra total de 834 estudiantes provenientes de la Universidad del Bío-Bío y la Universidad de Los Lagos, se tiene que dentro de la dimensión vocacional un $29.3 \%$ está en desacuerdo de que la vocación para ser profesor surgió de la interacción con profesores durante la etapa escolar, además de estar en desacuerdo en que esta vocación haya sido influida por buenos profesores que lo educaron durante la etapa escolar, esto con un 25.4\%. E1 70\% de los estudiantes, declararon estar en desacuerdo en que la vocación haya sido influida por los padres o algún familiar que se desempeñó en la profesión docente. Un 73.4\% de los estudiantes considera estar en desacuerdo con la afirmación de que la vocación no es requisito indispensable para ejercer la profesión docente. Por último, el 39.2\% de los estudiantes menciona estar desacuerdo en que la vocación docente se desarrolla preferentemente en el ejercicio profesional.

Dentro del ejercicio profesional, como dimensión, todos los ítem sobre el 80\% de los estudiantes muestran estar de acuerdo con que un profesor debe ser responsable de motivar, que representa autoridad, transmite conocimiento, comunica conocimiento cultural, planifica, debe ser un modelo de conducta, valores y de sabiduría, que debe tener altas capacidades cognitivas y de personalidad para el desarrollo de la profesión docente, junto a la escuela debe considerar a la familia, sociedad, grupos de pares y medios de comunicación para optimizar aprendizajes. Sin embargo, un 35.7\% de los estudiantes considera que calificar no es una de las principales funciones del profesor dentro del sistema escolar. De acuerdo con lo anterior, complementamos lo expresado con la definición de Pavié (2011), quien 
identifica este aspecto -específicamente la definición de competencia profesional docente- como “... aquel grupo de conocimientos, técnicas de enseñanza y rasgos personales que, mediante su aplicación y transferencia oportuna, le permite al profesor mejorar la calidad del aprendizaje de sus alumnos en un ámbito específico del saber" (Pavié, 2011, p. 78).

En lo referido a la dimensión de autoimagen y prestigio social, un $25 \%$ de los estudiantes menciona no tener información con respecto a si la profesión docente es elegida mayoritariamente por el género femenino, otro $25 \%$ de los estudiantes tampoco mantiene información en si el prestigio social y económico abunda mayoritariamente en los catedráticos universitarios que en profesores de aulas parvularias, básicas y medias.

El 77\% de los encuestados menciona estar en desacuerdo con que ser profesor(a), actualmente, es valorado por la sociedad chilena, tanto como la de países nórdicos. Un $42 \%$ menciona que no es valorado por las familias de sus estudiantes y un $44 \%$ menciona que tampoco es legalmente valorado por el gobierno, el MINEDUC (Ministerio de Educación de Chile) y los políticos. Además, un 56\% está en desacuerdo con que la profesión docente es elegida mayoritariamente por el género femenino. Un 47\% está en desacuerdo con que ser profesor, actualmente, tiene el respeto de sus autoridades directas y de sus estudiantes. Por último, se observa que un $39 \%$ considera que desempeñarse como profesor(a) no le dará mucho prestigio social.

A continuación, se presenta la tabla 3 que muestra el detalle de las respuestas obtenidas en términos globales por los estudiantes de las dos universidades. Se observa el porcentaje de respuestas de estudiantes que declararon no tener información del tema, aquellas en que estuvieron en desacuerdo y el porcentaje asociado a las respuestas en que estuvieron de acuerdo con la afirmación por cada una de las tres dimensiones e ítems. 
Tabla 3

Distribución de respuestas por ítem y dimensión

\begin{tabular}{|c|c|c|c|c|}
\hline Dimensión & ítem & $\begin{array}{l}\text { Sin } \\
\text { información } \\
\text { del tema }\end{array}$ & Desacuerdo & De acuerdo \\
\hline \multirow{10}{*}{ Vocacional } & $\begin{array}{l}\text { Elegí esta carrera porque me gusta enseñar y } \\
\text { ayudar a formar personas }\end{array}$ & $0.2 \%$ & $1.8 \%$ & $98 \%$ \\
\hline & $\begin{array}{l}\text { Elegí esta carrera porque me atrae, motiva, } \\
\text { satisface la profesión docente }\end{array}$ & $0.5 \%$ & $2.4 \%$ & $97.1 \%$ \\
\hline & $\begin{array}{l}\text { Pienso que nací con vocación para ser profesor. } \\
\text { Espero desarrollarla cuando sea profesional de la }\end{array}$ & & & \\
\hline & Educación & $1.3 \%$ & $12.6 \%$ & $86.1 \%$ \\
\hline & $\begin{array}{l}\text { Mi vocación de profesor surgió de la interacción } \\
\text { con mis profesores durante la etapa escolar }\end{array}$ & $1 \%$ & $29.3 \%$ & $69.8 \%$ \\
\hline & $\begin{array}{l}\text { Mi vocación de profesor fue influida por buenos } \\
\text { profesores que me educaron/hicieron clases, } \\
\text { durante la etapa escolar }\end{array}$ & $1.4 \%$ & $25.4 \%$ & $73.1 \%$ \\
\hline & $\begin{array}{l}\text { Mi vocación de profesor fue influida porque mi } \\
\text { padre, madre o algún pariente se desempeñó en la } \\
\text { profesión docente }\end{array}$ & $8.8 \%$ & $69.7 \%$ & $21.6 \%$ \\
\hline & $\begin{array}{l}\text { La vocación no es requisito indispensable para } \\
\text { ejercer la profesión docente }\end{array}$ & $7.7 \%$ & $73.4 \%$ & $18.9 \%$ \\
\hline & $\begin{array}{l}\text { La vocación docente se desarrolla preferentemente } \\
\text { en el ejercicio de la profesión }\end{array}$ & $3.7 \%$ & $39.2 \%$ & $57.1 \%$ \\
\hline & $\begin{array}{l}\text { Seleccioné una carrera de Pedagogía, pues tengo } \\
\text { preferencia por las personas y las Ciencias Sociales }\end{array}$ & $1.3 \%$ & $15.3 \%$ & $83.3 \%$ \\
\hline \multirow{6}{*}{ Ejercicio profesional } & $\begin{array}{l}\text { El profesor es responsable de motivar a sus } \\
\text { estudiantes en el proceso enseñanza aprendizaje } \\
\text { en el aula }\end{array}$ & $0.2 \%$ & $1.9 \%$ & $97.8 \%$ \\
\hline & $\begin{array}{l}\text { El profesor representa la autoridad de la sociedad } \\
\text { en la sala de clase }\end{array}$ & $1.2 \%$ & $18 \%$ & $80.8 \%$ \\
\hline & $\begin{array}{l}\text { Un profesor trasmite el conocimiento de la } \\
\text { sociedad en la sala de clase }\end{array}$ & $1 \%$ & $7.9 \%$ & $91.1 \%$ \\
\hline & $\begin{array}{l}\text { Un profesor comunica el conocimiento cultural en } \\
\text { la sala de clase }\end{array}$ & $0.6 \%$ & $3.8 \%$ & $95.6 \%$ \\
\hline & $\begin{array}{l}\text { Planificar es uno de los principales roles de los } \\
\text { profesores en el sistema escolar }\end{array}$ & $2.6 \%$ & $13.3 \%$ & $84.1 \%$ \\
\hline & $\begin{array}{l}\text { Calificar es una de las principales funciones de los } \\
\text { profesores en el sistema escolar }\end{array}$ & $1.6 \%$ & $35.7 \%$ & $62.7 \%$ \\
\hline
\end{tabular}


Tabla 3

Distribución de respuestas por ítem y dimensión

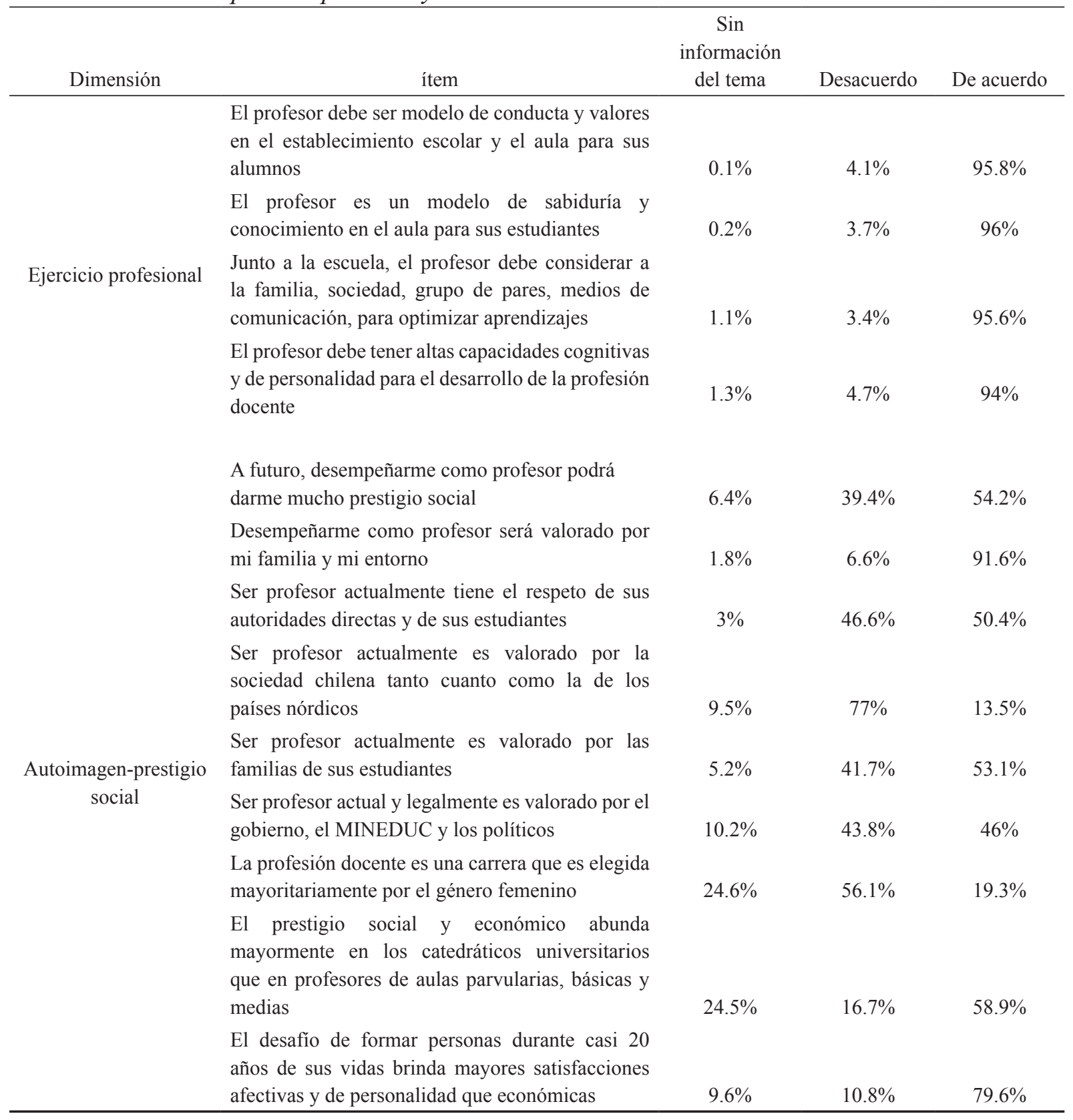

Nota: Elaboración propia. 


\section{Presentación de datos por dimensiones según universidad}

De acuerdo con la distribución de respuestas de los estudiantes en ambas universidades, se puede observar que en los porcentajes asociados a cada una de las tres categorías destacadas son muy similares entre ellas. Para una mejor interpretación de resultados de las categorías, se han considerado los ítems que mantienen un $20 \%$ o más de respuestas "Sin información del tema" o de respuestas en "Desacuerdo".

Por tanto, se tiene que dentro de la categoría "Sin información del tema" solo en la en la dimensión de autoimagen-prestigio social ambas universidades reflejan una falta de información con respecto a que la profesión docente es una carrera elegida mayoritariamente por el género femenino con un $23.3 \%$ en la Universidad del Bío-Bío y un 26\% en la Universidad de Los Lagos. También, se refleja una falta de información en que el prestigio social y económico abunda mayoritariamente en los catedráticos universitarios que en profesores de aulas parvularias, básicas y medias con un $20 \%$ en la Universidad del Bío-Bío y un 29.7\% en la Universidad de Los Lagos.

Para la categoría "Desacuerdo", se tiene que dentro de la dimensión asociada a la Vocación tanto los estudiantes de Universidad del Bío-Bío como la Universidad de Los Lagos un porcentaje considerable declara estar en desacuerdo en que la vocación para ser un profesor surgió de la interacción con profesores de su etapa escolar con un $26 \%$ y un $33.1 \%$, respectivamente, o que haya sido influida por buenos profesores que le realizaron clases durante la etapa escolar. Obtuvo un porcentaje desacuerdo de 22.9 \% en la Universidad del Bío-Bío y un $28.4 \%$ en la Universidad de Los Lagos.

Además, un alto porcentaje de estudiantes declara estar en desacuerdo con que la vocación para ser profesor fue influida por que la madre, padre o algún pariente se desempeñó en la profesión docente (69.6\% Universidad del Bío-Bío y un 69.8\% en la Universidad de Los Lagos). Asimismo, un 79.1\% en la Universidad del Bío Bío y un 66.7\% en la Universidad de Los Lagos se encuentran en desacuerdo con que la vocación no es un requisito indispensable para ejercer la profesión docente. Finalmente, cerca del 40\% de los estudiantes de ambas Universidades está en desacuerdo con que la vocación docente se desarrolla de forma preferente en el ejercicio de la profesión.

En la dimensión de ejercicio profesional, se observa que solo la Universidad de Los Lagos muestra un porcentaje sobre un $20 \%$ en estar en desacuerdo en que el profesor representa la autoridad de la sociedad en la sala de clases. Sin embargo, dentro de la misma dimensión, ambas universidades consideran estar en desacuerdo con que calificar es una de las principales funciones de los profesores en el sistema escolar, con un 37.5\% en la Universidad del Bío-Bío y un 33.3\% en la Universidad de Los Lagos.

Finalmente, en la dimensión de autoimagen-prestigio social se tiene que un $42.9 \%$ en la Universidad del Bío-Bío y un 35.4\% en la Universidad de Los Lagos está en desacuerdo con que, a futuro, el desempeñarse como profesor podrá darle mucho prestigio social. Dentro de esta dimensión, se tiene además que ambas universidades mantienen porcentajes en desacuerdo sobre un $40 \%$ en que ser profesor actualmente tiene el respeto de sus autoridades directas y de sus estudiantes, sobre un $74 \%$ de los estudiantes de las dos Universidades considera estar desacuerdo en que ser profesor actualmente es valorado por la sociedad chilena tanto como la de los países nórdicos. Además, un 44\% en la Universidad del Bío-Bío y un $39 \%$ en la Universidad de Los Lagos está en desacuerdo en que ser profesor actualmente es valuado por las familias de sus estudiantes. Sobre el $41 \%$ de los estudiantes, considera además estar en desacuerdo en 
que ser profesor actual y legalmente es valorado por el gobierno, el Mineduc y los Políticos. Por último, en la dimensión de autoimagen-prestigio social un 55.6\% en la Universidad del Bío-Bío y un 56.8\% en la Universidad de Los Lagos están en desacuerdo con que la profesión docente es una carrera que es escogida mayoritariamente por el género femenino.

A continuación, se presentan las tablas 4, 5 y 6, las cuales muestran el detalle de las respuestas obtenidas por los estudiantes por cada universidad. Se observa el porcentaje de respuestas de estudiantes que declararon no tener información del tema, aquellas en que estuvieron en desacuerdo y el porcentaje asociado a las respuestas en que estuvieron de acuerdo con la afirmación por cada una de las tres dimensiones e ítems, además de la incorporación de la prueba $U$ de Mann Whitney para determinar si existen diferencias estadísticamente significativas entre las distribuciones de respuestas de las dos universidades.

Se ha determinado que en las dimensiones de vocación, ejercicio profesional y autoimagen y prestigio social existen dos ítems por cada uno de ellos, que muestran diferencias estadísticamente significativas en la distribución de respuestas entre la Universidad del Bío-Bío y la Universidad de Los Lagos. De acuerdo con lo anterior, las diferencias en la distribución se encuentran específicamente en que la vocación para ser profesor surgió de la interacción con los profesores que el estudiante tuvo en su etapa escolar $(p=.008)$ y que haya sido influida por buenos profesores que le realizaron clases durante su etapa escolar $(p=.025)$. Se puede visualizar en la tabla 4 .

\section{Tabla 4}

\section{Distribución de respuestas por universidad en la dimensión vocacional}

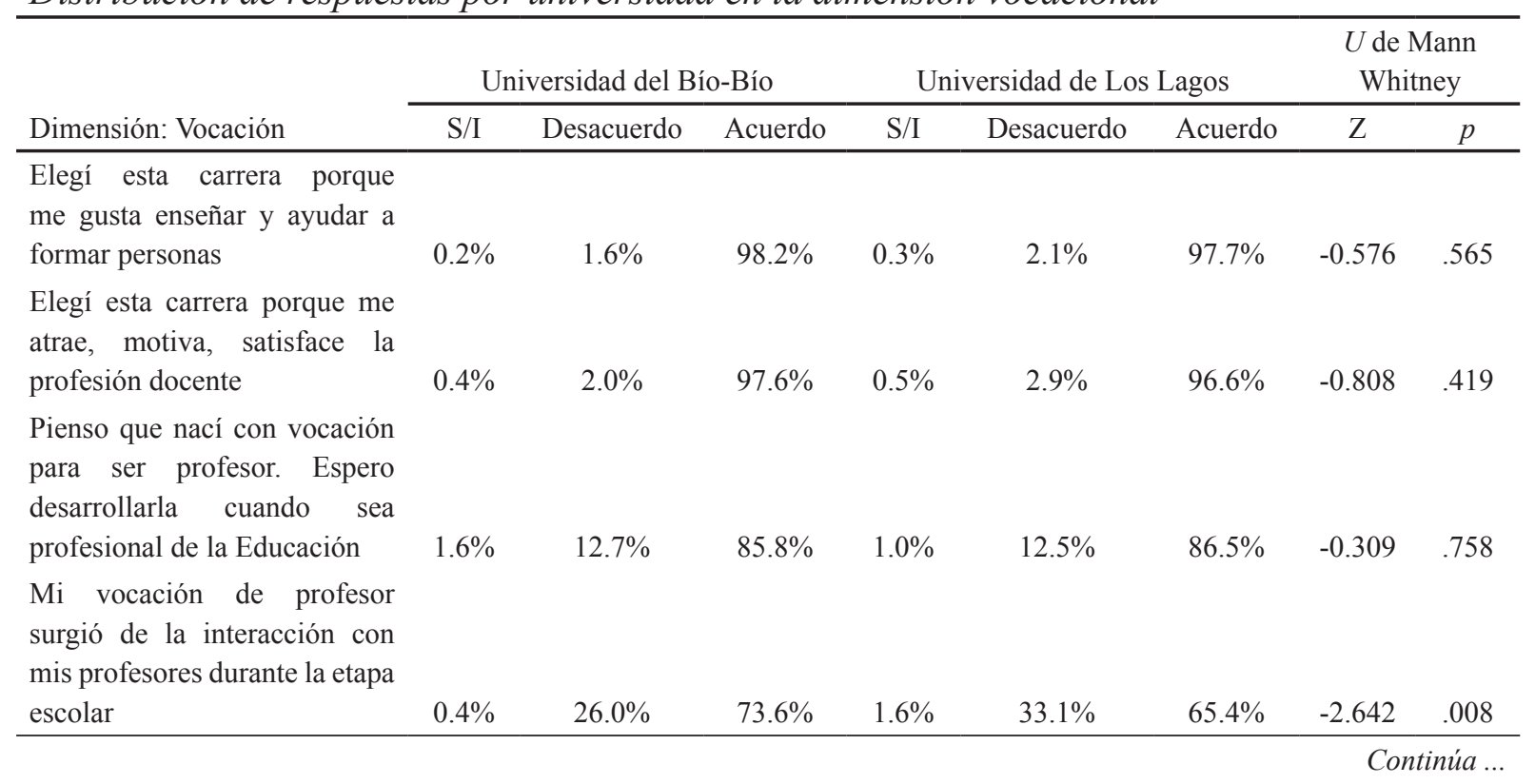




\section{Tabla 4}

Distribución de respuestas por universidad en la dimensión vocacional

\begin{tabular}{|c|c|c|c|c|c|c|c|c|}
\hline \multirow[b]{2}{*}{ Dimensión: Vocación } & \multicolumn{3}{|c|}{ Universidad del Bío-Bío } & \multicolumn{3}{|c|}{ Universidad de Los Lagos } & \multicolumn{2}{|c|}{$\begin{array}{c}U \text { de Mann } \\
\text { Whitney }\end{array}$} \\
\hline & $\mathrm{S} / \mathrm{I}$ & Desacuerdo & Acuerdo & $\mathrm{S} / \mathrm{I}$ & Desacuerdo & Acuerdo & $\mathrm{Z}$ & $p$ \\
\hline $\begin{array}{l}\text { Mi vocación de profesor fue } \\
\text { influida por buenos profesores } \\
\text { que me educaron/hicieron } \\
\text { clases, durante la etapa escolar }\end{array}$ & $0.9 \%$ & $22.9 \%$ & $76.2 \%$ & $2.1 \%$ & $28.4 \%$ & $69.5 \%$ & -2.239 & .025 \\
\hline $\begin{array}{l}\text { Mi vocación de profesor fue } \\
\text { influida porque mi padre, } \\
\text { madre o algún pariente se } \\
\text { desempeñó en la profesión } \\
\text { docente }\end{array}$ & $7.8 \%$ & $69.6 \%$ & $22.7 \%$ & $9.9 \%$ & $69.8 \%$ & $20.3 \%$ & -1.176 & .240 \\
\hline $\begin{array}{l}\text { La vocación no es requisito } \\
\text { indispensable para ejercer la } \\
\text { profesión docente }\end{array}$ & $4.9 \%$ & $79.1 \%$ & $16.0 \%$ & $10.9 \%$ & $66.7 \%$ & $22.4 \%$ & -0.323 & .747 \\
\hline $\begin{array}{l}\text { La vocación docente se } \\
\text { desarrolla preferentemente en } \\
\text { el ejercicio de la profesión }\end{array}$ & $3.6 \%$ & $40.0 \%$ & $56.4 \%$ & $3.9 \%$ & $38.3 \%$ & $57.8 \%$ & -0.335 & .738 \\
\hline $\begin{array}{l}\text { Seleccioné una carrera } \\
\text { de Pedagogía, pues tengo } \\
\text { preferencia por las personas y } \\
\text { las Ciencias Sociales }\end{array}$ & $1.1 \%$ & $13.3 \%$ & $85.6 \%$ & $1.6 \%$ & $17.7 \%$ & $80.7 \%$ & -1.865 & .062 \\
\hline
\end{tabular}

Nota: S/I corresponde a sin información del tema.

En la dimensión de ejercicio profesional, tal como se ve visualiza en la tabla 5, las diferencias se encuentran en que el profesor representa la autoridad de la sociedad en la sala de clase $(p=.015)$ y que el profesor debe ser modelo de conducta y valores en el establecimiento escolar y el aula para sus alumnos $(p=.041)$. 


\section{Tabla 5}

Distribución de respuestas por universidad en la dimensión ejercicio profesional

\begin{tabular}{|c|c|c|c|c|c|c|c|c|}
\hline \multirow{2}{*}{$\begin{array}{l}\text { Dimensión: ejercicio } \\
\text { profesional }\end{array}$} & \multicolumn{3}{|c|}{ Universidad del Bío-Bío } & \multicolumn{3}{|c|}{ Universidad de Los Lagos } & \multicolumn{2}{|c|}{$\begin{array}{l}U \text { de Mann } \\
\text { Whitney }\end{array}$} \\
\hline & $\mathrm{S} / \mathrm{I}$ & Desacuerdo & Acuerdo & $\mathrm{S} / \mathrm{I}$ & Desacuerdo & Acuerdo & Z & $p$ \\
\hline $\begin{array}{l}\text { El profesor es responsable } \\
\text { de motivar a sus estudiantes } \\
\text { en el proceso enseñanza- } \\
\text { aprendizaje en el aula } \\
\text { El profesor representa la } \\
\text { autoridad de la sociedad en la } \\
\text { sala de clase }\end{array}$ & $0.0 \%$ & $2.4 \%$ & $97.6 \%$ & $0.5 \%$ & $1.3 \%$ & $98.2 \%$ & -0.603 & .547 \\
\hline $\begin{array}{l}\text { Un profesor trasmite el } \\
\text { conocimiento de la sociedad } \\
\text { en la sala de clase }\end{array}$ & $0.4 \%$ & $7.8 \%$ & $91.8 \%$ & $1.6 \%$ & $8.1 \%$ & $90.4 \%$ & -0.758 & .448 \\
\hline $\begin{array}{l}\text { Un profesor comunica el } \\
\text { conocimiento cultural en la } \\
\text { sala de clase }\end{array}$ & $0.4 \%$ & $4.4 \%$ & $95.1 \%$ & $0.8 \%$ & $3.1 \%$ & $96.1 \%$ & -0.672 & .502 \\
\hline $\begin{array}{l}\text { Planificar es uno de } \text { los } \\
\text { principales roles de } \\
\text { profesores en el } \\
\text { escolar }\end{array}$ & $1.8 \%$ & $14.4 \%$ & $83.8 \%$ & $3.6 \%$ & $12.0 \%$ & $84.4 \%$ & -0.111 & .911 \\
\hline $\begin{array}{l}\text { Calificar es una de las } \\
\text { principales funciones de } \\
\text { los profesores en el sistema } \\
\text { escolar }\end{array}$ & $0.9 \%$ & $37.8 \%$ & $61.3 \%$ & $2.3 \%$ & $33.3 \%$ & $64.3 \%$ & -0.711 & .477 \\
\hline $\begin{array}{l}\text { El profesor debe ser modelo } \\
\text { de conducta y valores en el } \\
\text { establecimiento escolar y el } \\
\text { aula para sus alumnos }\end{array}$ & $0.0 \%$ & $2.9 \%$ & $97.1 \%$ & $0.3 \%$ & $5.5 \%$ & $94.3 \%$ & -2.043 & .041 \\
\hline $\begin{array}{l}\text { El profesor es un modelo de } \\
\text { sabiduría y conocimiento en } \\
\text { el aula para sus estudiantes }\end{array}$ & $0.2 \%$ & $3.6 \%$ & $96.2 \%$ & $0.3 \%$ & $3.9 \%$ & $95.8 \%$ & -0.287 & .774 \\
\hline
\end{tabular}




\section{Tabla 5}

Distribución de respuestas por universidad en la dimensión ejercicio profesional

\begin{tabular}{|c|c|c|c|c|c|c|c|c|}
\hline \multirow{2}{*}{$\begin{array}{l}\text { Dimensión: ejercicio } \\
\text { profesional }\end{array}$} & \multicolumn{3}{|c|}{ Universidad del Bío-Bío } & \multicolumn{3}{|c|}{ Universidad de Los Lagos } & \multicolumn{2}{|c|}{$\begin{array}{l}U \text { de Mann } \\
\text { Whitney }\end{array}$} \\
\hline & $\mathrm{S} / \mathrm{I}$ & Desacuerdo & Acuerdo & $\mathrm{S} / \mathrm{I}$ & Desacuerdo & Acuerdo & Z & $p$ \\
\hline $\begin{array}{l}\text { Junto a la escuela, el profesor } \\
\text { debe considerar a la familia, } \\
\text { sociedad, grupo de pares, } \\
\text { medios de comunicación, para } \\
\text { optimizar aprendizajes }\end{array}$ & $0.9 \%$ & $4.2 \%$ & $94.9 \%$ & $1.3 \%$ & $2.3 \%$ & $96.4 \%$ & -1.000 & .317 \\
\hline $\begin{array}{l}\text { El profesor debe tener altas } \\
\text { capacidades cognitivas y de } \\
\text { personalidad para el desarrollo } \\
\text { de la profesión docente }\end{array}$ & $0.7 \%$ & $4.2 \%$ & $95.1 \%$ & $2.1 \%$ & $5.2 \%$ & $92.7 \%$ & -1.488 & .137 \\
\hline
\end{tabular}

Nota: S/I corresponde a sin información del tema.

Por último, en la dimensión de autoimagen-prestigio social de acuerdo con la tabla 6 , las diferencias de respuestas entre las dos universidades se encuentran en que el prestigio social y económico abunda mayormente en los catedráticos universitarios que en profesores de aulas parvularias, básicas y medias $(p<.001)$ y que ser profesor actual y legalmente es valorado por el gobierno, el MINEDUC y los políticos $(p=.004)$. 


\section{Tabla 6}

Distribución de respuestas por universidad en la dimensión autoimagen-prestigio social

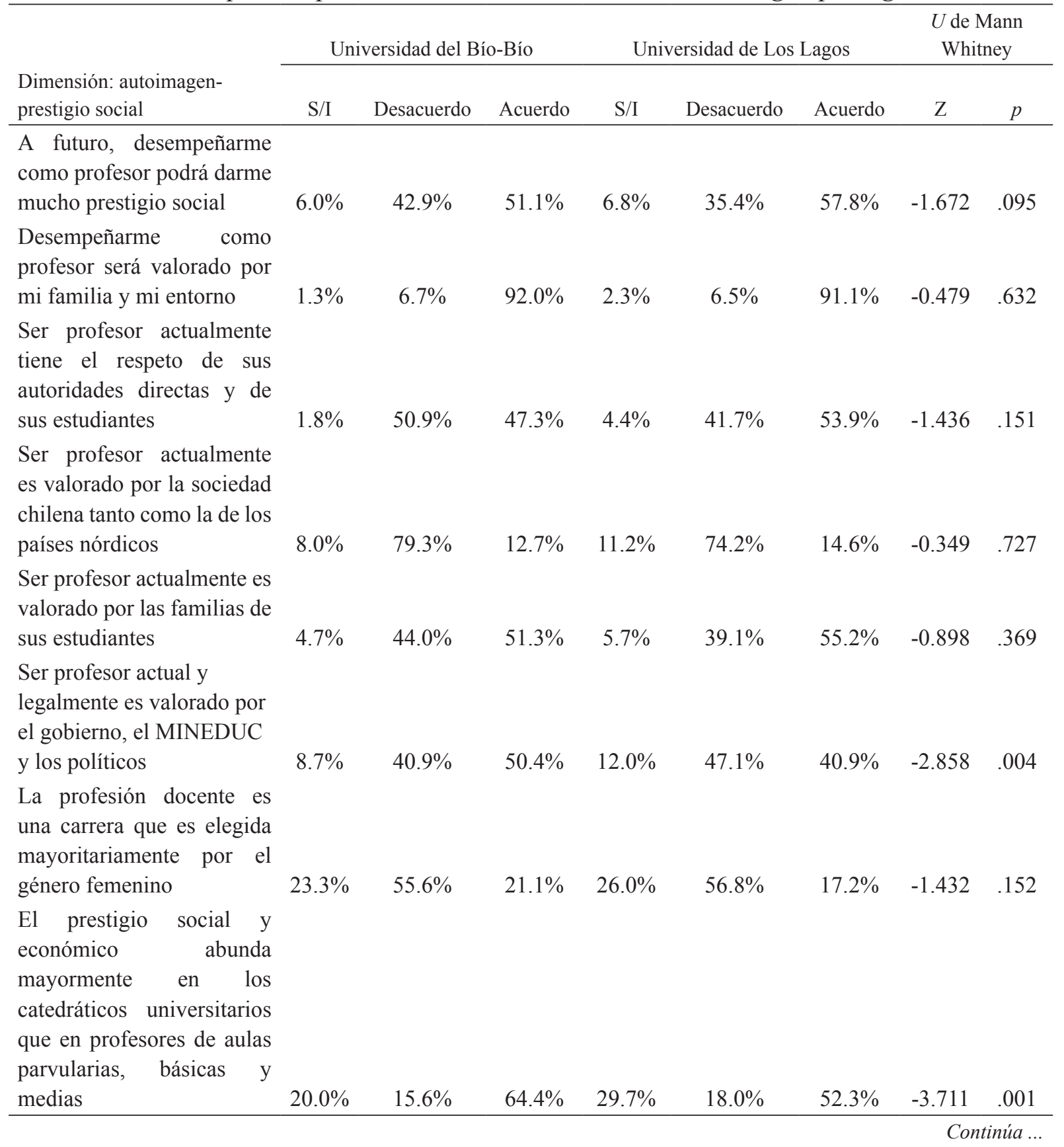


Tabla 6

Distribución de respuestas por universidad en la dimensión autoimagen-prestigio social

\begin{tabular}{|c|c|c|c|c|c|c|c|c|}
\hline \multirow[b]{2}{*}{$\begin{array}{l}\text { Dimensión: autoimagen- } \\
\text { prestigio social }\end{array}$} & \multicolumn{3}{|c|}{ Universidad del Bío-Bío } & \multicolumn{3}{|c|}{ Universidad de Los Lagos } & \multicolumn{2}{|c|}{$\begin{array}{l}\text { U de Mann } \\
\text { Whitney }\end{array}$} \\
\hline & $\mathrm{S} / \mathrm{I}$ & Desacuerdo & Acuerdo & $\mathrm{S} / \mathrm{I}$ & Desacuerdo & Acuerdo & Z & $\mathrm{p}$ \\
\hline $\begin{array}{l}\text { El desafío de formar } \\
\text { personas durante casi } 20 \\
\text { años de sus vidas brinda } \\
\text { mayores satisfacciones } \\
\text { afectivas y de personalidad } \\
\text { que económicas }\end{array}$ & $7.3 \%$ & $11.1 \%$ & $81.6 \%$ & $12.2 \%$ & $10.4 \%$ & $77.3 \%$ & -1.706 & .088 \\
\hline
\end{tabular}

Nota: S/I corresponde a sin información del tema.

\section{Discusión}

Se puede postular, a priori, que la representación social acerca de la profesión docente se organiza al tener como base de la noción de enseñanza como nodo central de representación; en consecuencia, desde este concepto, se articula un conjunto de otras valoraciones (actitud) e ideas (información), que se han detectado en este estudio, las cuales configurarían un sistema periférico al núcleo (Abric, 2001).

La Teoría sobre las Representaciones Sociales (Jodelet, 1986; Moscovici, 1979) es una teoría del sentido común, que otorga la posibilidad de explicar un objeto. Por esto, los factores de la periferia al núcleo (enseñanza) conforman un sistema que permite, entre otras cosas, explicar y comprender la idea figurativa más estable de las dimensiones abordadas en este trabajo; por tanto, configuran un conocimiento y/o teoría sobre la profesión docente.

De acuerdo con lo planteado previamente, se puede inferir que los sujetos estudiados representan la profesión docente como el sujeto que enseña, o al colectivo de sujetos que enseñan, en un espacio escolarizado identificado como aula. Al considerar esto como punto de inicio, se vislumbra que, socialmente, se representa la profesión como un sujeto que ejerce de forma individual. La acción de naturaleza vocacional se propone ayudar a sus estudiantes a que aprendan y para estos efectos deben tener competencias y cualidades personales, conocimiento y técnicas para enseñar; también, conocimiento y habilidades para comprender a los estudiantes y cómo aprenden (Psicología). Además, proporciona satisfacción personal a los sujetos que ejercen la profesión, pero que su trabajo no tiene retribución en cuanto a su valoración social. Más aún, en trabajos recientes se sigue evidenciando que "... la responsabilidad del maestro y la maestra sigue estando centrada en su función de enseñar y no es cuestiones conexas a ella" (Cabeza, Zapata \& Lombana, 2018, p. 9). Por tanto, el que la enseñanza sea postulada como nodo central de la representación sobre la profesión docente no es ajeno al largo recorrido histórico del colectivo denominado docente, puesto que la enseñanza es el origen del colectivo $\mathrm{y}$, al mismo tiempo, el principio y el fin organizador de su quehacer docente y profesional. 
Ahora bien, en función de lo expresado como principales hallazgos sobre la representación social de la profesión docente que han elaborado (constituido) cognitivamente la muestra estudiada, surge la pregunta natural de comprender cómo surgieron o de qué forma se configuraron dichas representaciones sociales en el colectivo de sujetos que inician su FID institucionalizada. Lo anterior toma en consideración el contexto social e histórico particular de nuestro sistema escolar, porque este escenario formativo debe haber tenido algún tipo o grado de influencia en la construcción de dicha representación de los sujetos estudiados y que inician su FID en la Universidad del Estado de Chile.

Por lo planteado hasta ahora, surge, entonces, la necesidad de continuar explorando con mayor profundidad las dimensiones presentadas en este estudio. Se amplía la cobertura de dicho estudio, sobre todo, con las universidades que forman a estudiantes en distintas carreras pedagógicas. Se propone desarrollar todo esto en una nueva investigación.

\section{Conclusiones}

En términos generales, el presente estudio tuvo como finalidad caracterizar las representaciones sociales sobre la profesión docente que han elaborado estudiantes que ingresan a una carrera de Pedagogía durante el año académico 2018. Más específicamente, las representaciones sociales sobre la vocación docente, el ejercicio profesional docente y la autoimagen-prestigio social de la profesión docente.

En coherencia con el marco teórico de Moscovici (1979), quien señala que la representación social se construye en torno a tres dimensiones (la información, el campo representado y la actitud), el presente estudio trata de indagar sobre el conocimiento no especializado y de sentido común que han elaborado los futuros profesores al inicio de su FID. Dados los propósitos de la indagación, se trabajó particularmente en dos de las dimensiones: información y valoración (actitud) en torno a la profesión docente, bajo la premisa que estas ideas se han construido de manera natural, y se encontrarían ancladas cognitiva y actitudinalmente antes de comenzar sus saberes especializados.

En este contexto, contar con esta información sobre las representaciones sociales resulta de interés, dado que es el punto de entrada para que las instituciones formadoras puedan construir y/o reconstruir conocimientos (saberes) especializados de la profesión, bajo el supuesto que ello permitirá un futuro desempeño profesional más pertinente a las necesidades de los saberes especializados y las demandas de las políticas actuales sobre la profesión docente.

Al revisar los resultados entre las dos universidades en estudio, la tendencia de respuestas en ambas resultan ser las mismas, por lo que se puede concluir que un alto porcentaje de estudiantes de las dos universidades está en desacuerdo con varias afirmaciones de los ítems en vocación, específicamente se resalta en que la vocación para ser profesor no fue influida por que el padre, madre o algún pariente se desempeñó en la profesión docente y que la vocación sí es un requisito indispensable para ejercer la profesión docente. Además, el 97\% de los estudiantes eligió la carrera docente porque le gusta enseñar, ayudar a formar personas, le atrae, le motiva y le satisface.

Dentro del ejercicio profesional, las dos universidades declaran estar en desacuerdo con el hecho de que calificar es una de las principales funciones de los profesores en el sistema escolar. Asimismo, sobre el 95\% de los estudiantes cree que el profesor es responsable de motivar, comunicar el conocimiento 
cultural, debe ser modelo de conducta y de valores, debe ser además un modelo de sabiduría y conocimiento en el aula y debe considerar diferentes factores familiares, sociales, comunicacionales para optimizar los aprendizajes.

En la dimensión de autoimagen y prestigio social se observan altos porcentajes en desacuerdo con afirmaciones en que ser profesor podrá darle mucho prestigio social, en que actualmente tiene el respeto de sus autoridades y sus estudiantes, que es valorado por el gobierno y/o las familias de sus estudiantes, que es valorado por la sociedad chilena, tanto como las de países nórdicos y que la profesión docente es una carrera elegida mayoritariamente por el género femenino. Además, consideran que desempeñarse como profesor sí será valorado por su familia y entorno y que el desafío de forma personas durante casi 20 años les brindará mayores satisfacciones afectivas y de personalidad que económicas.

En relación con lo señalado en este apartado, se reitera que las representaciones sociales (RS) de cada dimensión abordada en este estudio son compartidas en general independiente de la carrera que se ha estudiado. Por lo anterior, creemos importante tomar en consideración el diseño de un plan de acompañamiento que aborde en conjunto, para estas carreras pedagógicas, los resultados a partir de este diagnóstico presentado.

Cabe, aquí, un espacio para conminar a los diversos actores de la FID a seguir reflexionando y problematizando sobre los diversos aspectos que involucran el buen desarrollo de dicha FID. Lo anterior se concreta desde lo conceptual, el desarrollo de modelos, las teorías y/o experiencias existosas para los estudiantes que deciden estudiar este tipo de carreras.

Finalmente, dentro de las limitaciones encontradas en este estudio, una de las principales está relacionada con que bien la muestra resulta representativa, lo ideal sería desarrollar un trabajo de investigación con cobertura más amplia, de nivel nacional con universidades del Estado que mantengan cobertura desde el principio de las macrozonas; es decir, desde norte al sur austral de país. En cuanto a propuestas de resolución en próximas investigaciones, se sugiere diseñar un sistema de aseguramiento de la calidad en instituciones de educación superior que ponga especial atención y tratamiento al trabajo con las carreras pedagógicas, sobre todo, porque en Chile es obligatorio que este tipo de programas formativos estén acreditados ante la Comisión Nacional de Acreditación (CNA) para su normal funcionamiento y la emisión de los títulos y los grados correspondientes.

\section{Referencias}

Abric, C. (2001). Metodología de recolección de las representaciones sociales. En J.C. Abric (2001). Prácticas sociales y representaciones. Filosofía y cultura contemporánea N. 16. México: Ediciones Coyoacán.

Álvarez, B., \& Ruiz-Casares, M. (Eds.) (1997). Evaluación y reforma educativa; opciones de política. Santiago de Chile: PREAL.

Araya, S. (2002). Las representaciones sociales: eje teórico para su discusión. Cuadernos de Ciencias Sociales, 127. Costa Rica: Facultad Latinoamérica de Ciencias Sociales FLACSO.

Ávalos, B. (2001). Docencia profesional y su ejercicio. La profesión de la docencia. Revista Calidad de la Educación, (15), 1-18. 
Ávalos, B., \& Sotomayor, C. (2012). Cómo ven su identidad los docentes chilenos. Perspectiva Educacional, Formación de Profesores 51(1), 77-95.

Ávalos, B. (2014). La formación inicial docente en Chile: tensiones entre políticas de apoyo y control. Estudios Pedagógicos, XL(1), 11-28.

Banchs, M. (1986). Concepto de representaciones sociales: análisis comparativo. Revista Costarricense de Psicología, (8-9), 27-40. Recuperado de http://rcps-cr.org/wp-content/uploads/2016/05/1986.pdf

Barber, M. \& Mourshed, M. (2008). Cómo hicieron los sistemas educativos con mejor desempeño del mundo para alcanzar sus objetivos. N. ${ }^{\circ}$ 41. PREAL, Santiago: CINDE. Recuperado de http://www.oei.es/pdfs/ documento_preal41.pdf

Berger, P., \& Luckmann, T. (1993). La construcción social de la realidad. Buenos Aires: Amorrortu (Trabajo original publicado en 1967).

Bristzman, D. P. (2003). Practice Makes Practice: a Critical Study of Learning to Teach (Rev. Ed.). NY: State University of New York Press.

Brunner, J. (1996). Investigación social y decisiones políticas: el mercado del conocimiento. Nueva Sociedad, 146, 108-121.

Cabeza L., Zapata, A., \& Lombana, J. (2018). Crisis de la profesión docente en Colombia: percepciones de aspirantes a otras profesiones. Educación y Educadores, 21(1), 51-72. doi: https://doi.org/10.5294/edu.2018.21.1.3

Caena, F. (2014). Initial teacher education in Europe: an overview of policy issues. European Commission. Recuperado de http://ec.europa.eu/dgs/education_culture/repository/education/policy/strategic-framework/ expert-groups/documents/initial-teacher-education en.pdf

Caine, V., \& Steeves, P. (2009). Imagining and playfulness in narrative inquiry. International Journal of Education \& the Arts, 10(25), 1-15.

Contreras, J. (1985). ¿El pensamiento o conocimiento del profesor? Una crítica a los postulados de las investigaciones sobre el pensamiento del profesor y sus implicaciones para la formación del profesorado. Revista de Educación, 277, 5-28.

Cassasus, J. (2003). La escuela y la (des)igualdad. Santiago: LOM.

Domínguez, F. (2001). Teoría de las representaciones. Apuntes. Nómadas. Revista Crítica de Ciencias Sociales y Jurídicas, 1(3), 1-16.

Durkheim, E. (2001). Las reglas del método sociológico. Madrid: Akal. (Trabajo original publicado en 1895).

Durkheim, E. (1987). La división del trabajo social. Madrid: Akal (Trabajo original publicado en 1897).

Eisner, E. (1998). El ojo ilustrado: indagación cualitativa y mejora de la práctica educativa. España: Paidós.

García, L., Domínguez, R., \& Del Toro Valencia, M. (2018). La profesionalización docente, responsabilidad ineludible en Educación Media Superior. Debates en Evaluación y Currículum/Congreso Internacional de Educación Currículum 2017 /Año 3, N. ${ }^{\circ}$ 3. Recuperado de http://posgradoeducacionuatx.org/pdf2017/A006.pdf 
Goetz, J., \& Lecompte, M. (1988). Etnografía y diseño cualitativo en investigación educativa. Madrid: Morata.

González, A. (2017). Diagnóstico del nivel vocacional a estudiantes de la Licenciatura en Educación Secundaria con especialidad en Telesecundaria. Memorias del Concurso Lasallista de Investigación, Desarrollo e innovación, 3(2), 29-34.

Jarauta, B. (2017). La construcción de la identidad profesional del maestro de primaria durante su formación inicial. El caso de la universidad de Barcelona. Profesorado. Revista de Currículum y Formación de Profesorado, 21(1), 103-122.

Jodelet, D. (1986). La representación social: fenómenos, conceptos y teoría. En S. Moscovici (Ed.), Psicología social II. Pensamiento y vida social. Psicología social y problemas sociales (pp. 469-494). Barcelona: Paidós. Recuperado de https://sociopsicologia.files.wordpress.com/2010/05/rsociales-djodelet.pdf

Kaplan, C. (1997). La inteligencia escolarizada. Buenos Aires: Miño y Dávila.

Latorre, A., Del Rincón, D., \& Amal, J. (1997). Bases Metodológicas de la Investigación Educativa. Barcelona: Edit. Hurtado.

Latorre, M. (2006). Nuevas miradas, viejos problemas: Las relaciones entre formación inicial y ejercicio profesional docente. Foro Educacional, 10, 41-63. Recuperado de https://dialnet.unirioja.es/servlet/ $\underline{\text { articulo? } \text { codigo }=2292721}$

Lobato, C. (2002). Psicología y asesoramiento vocacional. Revista de Psico-didáctica, 1(13), 117-130. Recuperado de http://redalyc.uaemex.mx/pdf/175/17501308.pdf

Marková. I. (1996). En busca de las dimensiones epistemológicas de las representaciones sociales. En D. Páez \& A. Blanco (Eds.), La teoría sociocultural y Psicología social actual (pp. 163-182). Madrid: Rogar.

Meo, A. (2010). Consentimiento informado, anonimato y confidencialidad en investigación social. La experiencia internacional y el caso de la Sociología en Argentina. Aposta. Revista de Ciencias Sociales, 44, 1-30. Recuperado de http://www.apostadigital.com/revistav3/hemeroteca/aines.pdf

Ministerio de Educación de Chile (MINEDUC) (2016). Ley N. ${ }^{\circ}$ 20.903. Crea el sistema de desarrollo profesional docente y modifica otras normas. Recuperado de https:/www.leychile.cl/Navegar?idNorma=1087343

Miranda, C. (2005). La autoestima profesional: una competencia mediadora para la innovación en las prácticas pedagógicas. REICE-Revista Electrónica Iberoamericana sobre Calidad, Eficacia y Cambio en Educación. $3(1), 858-873$.

Mora, M. (2002). La teoría de las representaciones sociales de Serge Moscovici. Athenea Digital, (2), 1-25. Recuperado de http://www.raco.cat/index.php/Athenea/article/viewFile/34106/33945

Moscovici, S. (1979). El psicoanálisis, su imagen y su público. Buenos Aires, Argentina: ANESA-HUEMUL.

Moscovici, S. (1998). The history and actuality of social representations. En U. Flick (Ed.), The psychology of the social (pp. 209-247). Cambridge: Cambridge U.P. 
Muñoz, J., González, M., \& Rodríguez, M. (2018). Los Contenidos de la formación continuada del profesorado: ¿qué docentes se están formando? Educación XX1, 21(1), 157-180. Recuperado de http://www.redalyc.org/ pdf/706/70653466008.pdf

Neiman, G., \& Quaranta, G. (2006). Los estudios de caso en la investigación sociológica. En I. Vasilachis (Comp.), Estrategias de investigación cualitativa (pp. 213-235). Buenos Aires: Gedisa.

Nuñez, I. (2004). La identidad de los docentes. Una mirada histórica en Chile, en Programa Interdisciplinario de Investigación en Educación (PIIE). Chile: Ministerio de Educación de Chile.

Pavié, A. (2011). Formación docente: hacia una definición del concepto de competencia profesional docente. REIFOP, 14(1), 67-80. Recuperado de https://dialnet.unirioja.es/servlet/articulo?codigo $=3678767$

Pozo, J.L. (2008). El cambio de las concepciones docentes como factor de la revolución educativa. Revista Educación, Comunicación, Tecnología. 3(5), 1-27.

Pozo, J.L. (2009). Adquirir una concepción compleja del conocimiento: creencias epistemológicas y concepciones del aprendizaje. En J. L. Pozo \& M. P. Pérez (Eds.), Psicología del estudiante universitario: La formación en competencias (pp. 70-86). Madrid: Morata.

Pozo, J.L. (2014). Psicología del aprendizaje humano. Adquisición de conocimiento y cambio personal. Madrid: Morata.

Recarey, S., Del Pino, J.L., \& Rodríguez, M. (2011). La orientación en el contexto educativo. La Habana: Editorial Pueblo y Educación.

Reimers, F. (2000). Educación, desigualdad y opciones de política en América Latina. Revista Iberoamericana de educación, 23, 21-50.

Rifo, M. (2013). Movimiento estudiantil, sistema educativo y crisis política actual en Chile. Polis Revista Latinoamericana, 12(36), 223-240.

Rivas, F. (1998). Psicología vocacional: enfoques de asesoramiento. Madrid: Editorial Morata.

Ruffinelli, A. (2016). Ley de desarrollo profesional docente en Chile: de la precarización sistemática a los logros, avances y desafíos pendientes para la profesionalización. Estudios pedagógicos, 42(4), 261-279. Recuperado de https://dx.doi.org/10.4067/S0718-07052016000500015

Russell, T. (2014). La práctica en la formación de profesores: tensiones y posibilidades en la experiencia de aprender a enseñar. Estudios Pedagógicos, 40, 223-238. Recuperado de https://dx.doi.org/10.4067/ $\underline{\text { S0718-07052014000200013 }}$

Ryans, D. (1967). Characteristics of teachers. Their description, comparison and appraisal. Washington: American Council of Education.

Sánchez, E. (2002). Elegir magisterio: entre la motivación, la vocación y la obligación. Escuela abierta. Revista de investigación educativa, 5, 99-120. Recuperado de https://idus.us.es/xmlui/handle/11441/46854

Sandoval, M. (2009). Educación de calidad y desempeño docente. Ánfora, 16(27),5-41. 
Sandoval, P., Bustos, R., Pinto, A., Pavié, A., Valdés, G., Maldonado, A.C., \& Rodríguez, F. (2019). Representaciones sobre la profesión docente que poseen estudiantes que ingresan a las Formación Inicial Docente en Universidades del Estado. Manuscrito inédito. Dpto. de Estudios y Desarrollo, Ministerio de Educación. Santiago de Chile.

Sandoval P., Maldonado A., Bustos R., Pavié A., Pinto A., Valdés, G., \& Rodríguez D.F. (2020). Informe Final Proyecto FONIDE $N^{\circ}$ 181800090: representaciones sobre la profesión docente que poseen estudiantes que ingresan a la formación inicial docente en universidades del estado.

Sebastián, V. (2012). Autoestima y autoconcepto docente. Revista Phainomenon, 1(11), 23-34.

Schaffer, C., Gleich-Bope, D., \& Copich, N. (2014). Urban Immersion: Changing Preservice Teacher Perceptions of Urban Schools. The Nebraska Educator: a Student- Led Journal. Recuperado de http://digitalcommons. unl.edu/cgi/viewcontent.cgi?article=1014\&context=nebeducator

Sotomayor, C. (2013). La identidad docente y sus significados. En B. Ávalos (Ed.) (2013). ¿Héroes o villanos? La profesión docente en Chile. Santiago: Editorial Universitaria.

Taylor, S., \& Bogdan, R. (1990). Introducción a los métodos cualitativos de investigación. Madrid: Paidós.

Vaillant, D. (2005). Formación de docentes en América Latina. Re-inventando el modelo tradicional. Barcelona: Ed. Octaedro.

Vaillant, D. (2007). Mejorando la formación y el desarrollo profesional docente en Latinoamérica. Revista Pensamiento Educativo, 41(2), 207-222

Valdebenito, L. (2011). La calidad de la educación en Chile: ¿un problema de concepto y praxis? revisión del concepto calidad a partir de dos instancias de movilización estudiantil (2006 y 2011). Revista del Centro Telúrico de Investigaciones teóricas, (1), 1-25.

Vélaz de Medrano, C., \& Vaillant, D. (2009). Aprendizaje y desarrollo profesional docente. Editado OEI - Fundación Santillana. Madrid, España. Recuperado de https://www.oei.es/historico/publicaciones/detalle_publicacion. php?id=2

Recibido: 07 de Agosto de 2019 Revisión recibida: 04 de Diciembre de 2019

Aceptado: 24 de Enero de 2020 


\section{Sobre las autoras y los autores:}

Pedro Rodrigo Sandoval Rubilar es Doctor en Ciencias de la Educación, académico asociado de la Universidad del Bío-Bío (Chile) desde 2008 a la fecha. Docente de posgrado (Magíster y Doctorado) en diferentes universidades del país; coordinado del Grupo de Investigación en Educación GIE (UBB Código GI-130823); presidente Red de Investigadores Noveles en Investigación Educativa (rinie.cl), autor y coautor de múltiples publicaciones indexadas en el área. Línea de especialización e investigación desarrolladas son en el ámbito del currículo y evaluación en Formación Inicial Docente.

Alex Richard Pavié Nova es Doctor en Educación, especialidad en Didáctica, Académico Asociado de la Universidad de Los Lagos (Chile). Se ha desempeñado como Académico en diversas universidades tanto en Chile como en el extranjero en áreas de Didáctica, Desarrollo Curricular y Evaluación de aprendizajes y Formación Inicial de Profesores respectivamente tanto en Magíster como en Doctorado. Líneas de investigación: formación inicial docente, evaluación de aprendizaje y modelos de análisis de textos escolares. Coinvestigador del proyecto "Fortalecimiento de la gestión de la calidad en las Universidades Chilenas. Resultados de tres décadas de aprendizaje nacional", GOP-CINDA (Centro Interuniversitario de Desarrollo), período 2019-2020.

Claudia Edelmira Rubio Benítez es Licenciada en Estadística, Ingeniera en Estadística. Profesional de la Universidad de Los Lagos (Chile). Se ha desempeñado como docente de Estadística en carreras del área de Educación, Salud y Tecnología, profesora guía de Seminario de título en la carrera de Pedagogía en Educación Media con Mención en Matemática y Computación. Líneas de investigación: análisis estadístico aplicado a la Educación. Actualmente, es directora del Dpto. de Análisis Institucional de la Universidad de Los Lagos (Chile).

Ana Carolina Maldonado Fuentes es Magíster en Ciencias de la Educación (1999). Académica en la Universidad del Bío-Bío desde 2008 a la fecha. Jefa de la Unidad de Gestión Curricular y Monitoreo de la Universidad del BíoBío (2010-2014). Líneas de investigación: formación inicial docente, evaluación de aprendizaje y comprensión lectora. Coinvestigador del proyecto Grupo de Investigación en Educación (GIE) (Código GI-130823) de la Universidad del Bío-Bío. Beca Conicyt- Doctorado Nacional/2017-21170257.

Claudia González-Castro es Académica Escuela de Pedagogía Universidad de Los Lagos. Entre sus líneas de investigación se encuentran la identidad profesional docente, las identidades postcoloniales y los estudios del discurso. 
